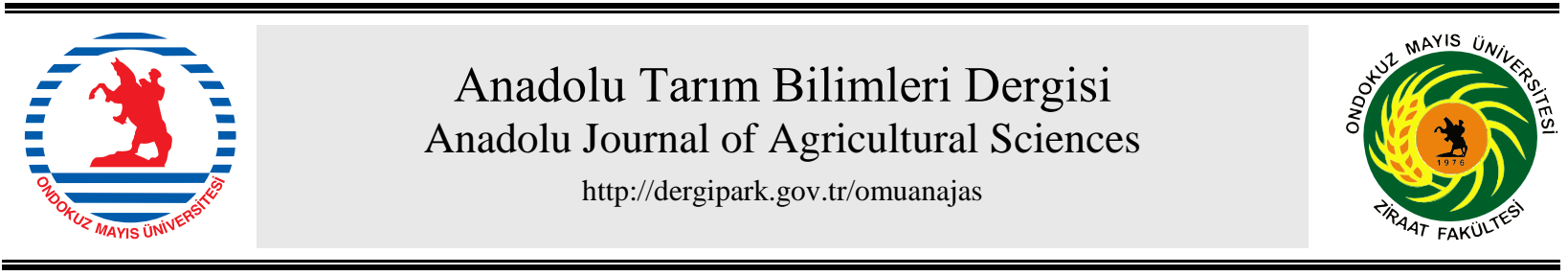

\title{
Araştırma/Research
}

Anadolu Tarım Bilim. Derg./Anadolu J Agr Sci, 35 (2020)

ISSN: 1308-8750 (Print) 1308-8769 (Online) doi: 10.7161/omuanajas.701109

\section{Mera topraklarında nem dağılımının konumsal ve zamansal değişiminin profil boyutunda izlenmesi}

\author{
(D) Oğuz Başkan ${ }^{\mathrm{a}^{*}}$ \\ Siirt Üniversitesi Ziraat Fakültesi Toprak Bilimi ve Bitki Besleme Bölümü, Siirt, Türkiye \\ *Sorumlu yazar/corresponding author: ogbaskan@yahoo.com
}

Geliş/Received 09/03/2020 Kabul/Accepted 26/03/2020

\begin{abstract}
ÖZET
Toprak nemi hidrolojik döngü içerisinde oransal olarak çok az olmasına rağmen tarımsal üretim ve hidrolojik süreçler için anahtar öneme sahiptir. Özellikle toprak profili derinliğinde toprak neminin zamansal değişiminin izlenmesi özellikle su kısıtı gözlenen kurak ve yarı kurak alanlar için çok daha önemlidir. Proje su toplama havzalarında arazi kullanım ve profil derinliğinin nem kapsamına etkisinin belirlenmesi amacıyla yürütülmüștür. Bu amaçla araștırma Ankara Yenimahalle Güvenç Havzasında, mera arazisinde horizon derinlikleri dikkate alınarak profil nem örneklemesi yapılmıştır. Jeoistatistik yöntemle nem dağılım haritaları oluşturulmuştur. Araştırma sonuçları profilde nem dağılımının konumsal ve zamansal olarak değiştiğini göstermiştir. Toprak bünyesi profil derinliğiyle birlikte nem dağılımını etkileyen ön önemli faktör olarak bulunmuştur. Toprak şartlarının kuruya doğru geçişi sırasında başlangıçta topoğrafya, nem kontrol eden etmen olurken daha sonra meteorolojik şartlar etkili parametreler olarak belirlenmiştir. Bünye içerisinde kil kapsamı azaldıkça atmosferik şartların etkisi artmıştır. Sonuçlar toprak neminin konumsal ve zamansal davranışı nedeniyle tek bir ölçümle tanımlanmasının doğru olmadığını, belirsizliği azaltmak için ıslak ve kurak dönemleri içeren sürekli gözlemlerin yapılması gerektiğini göstermiştir.
\end{abstract}

Monitoring spatial and temporal variation of moisture distribution in pasture soils at profile depth

\section{ABSTRACT}

Although soil moisture is proportionally small in the hydrological cycle, it is key factor for agricultural production and hydrological processes. In particular, monitoring the temporal change of soil moisture in soil profile depth is much more important especially for arid and semi-arid areas where water constraints are observed. The project was carried out in order to determine the effect of land use and profile depth on moisture content in watersheds. For this purpose, profile moisture sampling was carried out in Ankara Yenimahalle Güvenç Basin, taking into consideration of the horizon depth in pasture land. Soil moisture distribution maps were created by geostatistical method. Research results have shown that the distribution of moisture in the profile changes spatially and temporally. Soil texture has been found as a preliminary factor affecting moisture retention along with profile depth. During the movement of soil conditions to dry, topography was the first factor controlling humidity, while later meteorological conditions were determined as effective parameters. As the clay content decreased within the soil texture, the effect of atmospheric conditions increased. The results showed that it is not correct to define soil moisture with a single measurement due to its spatial and temporal behavior, therefore continuous observations including wet and dry periods should be made to reduce uncertainty.

Anahtar Sözcükler: Jeoistatistik Mera Profil derinliği Toprak nemi Yarı kurak alan
Keywords: Geostatistic Pasture Profile depth Soil moisture Semi arid area

(C) OMU ANAJAS 2020 


\section{Giriş}

Toprak özelliklerinde olduğu gibi hidrolojide de birçok değişken konumsal ve zamansal özellik gösterir. Toprak neminin yıl boyunca gösterdiği konumsal değişimin doğru ölçülmesi, özellikle tarım alanlarında ürün veriminin yanısıra, kimyasal gübrelerin ve pestisitlerin doğru miktarda ve zamanında kullanımı, yeraltı su kaynaklarının korunması, sulama planlaması, su kaynaklarının korunması gibi birçok faktörü doğrudan etkilemektedir.

Dinamik yapıs1 nedeniyle toprak nem kapsamı; meteorolojik şartlar, toprak bünyesi, profil derinliği, topoğrafya, arazi kullanımı, bitki örtüsü gibi birçok faktör tarafından kontrol edilir. Toprak nem dağılımının ekosistem içerisindeki önemi düşünüldüğünde yalnızca bir ölçüm değerinin konumsal yapıyı doğru yansıtması mümkün gözükmemektedir. Bu nedenle çeşitli ıslanma ve kuruma dönemlerinde birbirini izleyen ölçümlerin profil boyunca yapılması konumsal yapının zaman içerisinde ne oranda korunduğu veya değiştiğinin belirlenmesinde büyük önem taşımaktadır. Gerçekte işlemeli tarıma uygun olmayan mera alanları özel karakteristikleri nedeniyle izlenmesi ve korunmasi gereken önemli karasal ekosistemlerdir. Özellikle yarı kurak alanların çoğunlukta olduğu ülke topraklarında mera alanlarında uygun yönetim sistemlerinin işletilebilmesi önemlidir.

Büyük ölçeklerde uydu teknolojileri kullanılarak uzaktan algilama yolu ile toprak neminin izlenmesi kullanılan yöntemlerden biridir. Ancak uydu teknolojisi ile toprak neminin yalnızca toprak yüzeyinde izlenebilmesi, profil ölçeğinde detayların izlenmesinde ve değerlendirilmesinde yetersiz kalmaktadır (De Troch ve ark., 1996; De Lannoy ve ark., 2006). Uydu verileriyle birlikte, toprak neminin izlenmesinde algılayıcı (sensör) teknolojilerinin kullanıldığı (Fares ve ark., 2013; Robinson ve ark., 2008), toprak özelliklerinin yardımıyla nem tahmininin yapıldığı (Zhu ve ark., 2012) çalışmalar ile toprak nem dağılım haritaları oluşturulmakla birlikte bu haritalar yer gözlem istasyonlarının sayısına ve toprak özelliklerinin dinamik davranışlarına bağlı olarak değişik oranlarda belirsizlikler içermektedir. Toprak nem kapsamının profil boyutunda izlenmesi çalışmaları hala istenilen düzeye ulaşmamıştır.

Toprak su kapsamının konumsal yapısının havzalarda belirlenmesi için ölçüm noktaları arasında tahmin değerleri üreten kestirimlerin (interpolasyon) yapılması gerekmektedir. Konumsal tahmin yöntemlerine ihtiyaç duyulan bu alanda jeoistatistiksel yöntemler sıklıkla kullanılmaktadır. Yüzey toprağı (Famiglietti ve ark., 1998; Grayson ve Western, 1998; Cosh ve ark., 2006), profil boyutu (Wang ve ark., 2001; De Lannoy ve ark., 2006; Junior ve ark., 2006; Baskan ve ark., 2013) ve farklı topoğrafya şartlarında (Endale, 2005; Brocca ve ark., 2007) toprak nem kapsamının konumsal ve zamansal değişimiyle ilgili jeoistatistik yöntemler kullanılarak farklı şartlarda çeşitli çalışmalar yapılmıştır.

$\mathrm{Bu}$ çalışma ile doğal mera olarak kullanılan araştırma alanında toprak nem kapsamının profil derinliğinde gösterdiği konumsal ve zamansal değişimin belirlenmesi amaçlanmıştır.

\section{Materyal ve Yöntem}

\subsection{Araşttrma yeri}

Araştırmanın yürütüldüğü Güvenç Havzası AnkaraYenimahalle-Güvenç Köyünde Kayaönü Deresi üzerinde yapılan Güvenç Göletinin su toplama havzasıdır. Havza Ankara-İstanbul karayolunun 35. km'sinden 6.5 km doğuda, gölet ise köyün $2.5 \mathrm{~km}$ kuzeydoğusunda yer almaktadır. Havza yağış alanı $16.125 \mathrm{~km}^{2}$ 'dir. Deniz seviyesine göre yükseltisi 1053 metre olan havza çıkış yerinin enlemi $40^{\circ}$ $08^{\prime} 00^{\prime \prime}$ kuzey, boylamı $32^{0} 45^{\prime} 15^{\prime}$ ' doğudur.

\subsubsection{Toprak özellikleri ve arazi kullanımı}

Araştırma havzasında yapılan detaylı toprak etüt çalışması sonucunda 8 farklı toprak serisi tanımlanmıştır (Soil Survey Staff, 1999). Bu serilerin 4 tanesi Entisol, 3 tanesi Inceptisol ve 1 tanesi ise Vertisol ordosuna dahil edilmiştir (Dengiz ve Başkan, 2005). Bu ordolar içerisinde \%59.9 ile Entisoller en fazla alan kaplarken bunu sirasiyla \%34.2 ile Inceptisol ve \%1.7 ile Vertisol izlemektedir. Araştırmanın yürütüldüğü Acısu serisi toprakları Inceptisol ordosu içerisinde yer almaktadır. Derin profilli seri, eğimli arazi topoğrafyasındadır. Aşınım düzlüğünde oluşan Kervanpınar serisi havzanın en derin profilli topraklarıdır. Entisol ordosuna dahil edilen \%12-20 eğimli şiddetli erozyonlu Tabyabayır serisi toprakları ise havzanın profil derinliği en az olan topraklarıdır.

Havza alanının \%37.2 iyi mera, \%6.3' ü zayıf mera, \%49.7'si kuru tarım, \%2.5'i orman, \%2.6's1 fundalıkbahçe olarak kullanılmaktadır. Havza alanının \%1.7’ si ise terk edilmiş araziler oluşturmaktadır (Tekeli ve ark., 2004).

\subsection{2 İklim özellikleri}

Araştırma havzasının uzun yıllık (1984-2010) ortalama yıllık yağış, ortalama sıcaklık, nispi nem ve buharlaşma miktarı sirasiyla $474.4 \mathrm{~mm}, 11.4{ }^{\circ} \mathrm{C}$, \%64 ve $1232 \mathrm{~mm}$ olarak ölçülmüştür. Yağışların mevsimsel dağılımı \%22.8' i ilkbahar, \%30.1'i kış, \%23.3' ü sonbahar, \%13.9' u yaz aylarında olmuştur. Ortalama olarak en çok yağı̧̧ alan ay Nisan $(59.3 \mathrm{~mm})$ en az yă̆ı̧ al an ay ise Ağustos (12.4 mm) ayı olmuştur. 


\subsection{Toprak analizleri ve örnekleme}

Detaylı toprak etüt çalışması sonucunda belirlenen ve doğal mera alanı olarak kullanılan Acısu serisi $(0-85 \mathrm{~cm}$, Inceptisol ordosu) topraklarından horizon derinlikleri dikkate alınarak toprak nem örneklemesi y1l boyunca yağış gözlenen dönemlerde $5 \times 10 \mathrm{~m}$ aralıklarla profil boyunca yapılmış (Şekil 1) ve her ölçümde horizon derinlikleri dikkate alınarak her horizondan 100'er adet toprak örneği alınmıştır. Toprak buharlaşma kayıplarını engellemek için alınan nem örnekleri arazide tartılarak laboratuvara getirilmiştir. Araştırma alanında ayrıca her noktadan horizon derinliklerinde toprak örnekleri alınarak gravimetrik nem kapsamı belirlenmiştir. Toprak nem kapsamı kuru hacim ağırlığı değerleriyle çarpılarak hacimsel nem değerleri, derinlikle çarpılarak ise horizonda ve profildeki mm su kapsamı (Gardner, 1986), bünye (Bouyoucos 1951), kuru hacim ağırlığı (Blake ve Hartge 1986), organik karbon kapsamı (Jackson 1958) belirlenmiştir. Bitki su tüketimi Thornthwaite (1948) yöntemi kullanılarak hesaplanmıştır.

\subsubsection{Jeoistatistik analiz}

Toprak örneklerinin analizi sonunda elde edilen veriler jeoistatistik yöntem ile değerlendirilerek deneysel yarıvariogramlar oluşturulup toprak nem değerlerinin konumsal bağımlılık dereceleri belirlenmiştir. Jeoistatistiğin temelini oluşturan yarıvariogram modelle örnek çiftleri arasındaki konumsal yapıyı tanımlanmış, elde edilen model parametreleri bir sonraki aşama olan kestirim (interpolasyon) işleminde kullanılarak blok kriging yöntemi ile toprak neminin gözlem süresince araştırma alanı içerisindeki dağılım haritaları oluşturulmuştur (GS+ 9). Oluşturulan yarıvariogram modellerinin kaliteleri çapraz doğrulama sonucunda elde edilen ortalama mutlak hata (MAE) ve hata kareler ortalaması (MSE) değerleri ile kontrol edilmiştir (Eşitlik 1, 2).

$$
\begin{aligned}
& M A E=\frac{1}{n} \sum_{i=1}^{n}\left|X_{g o ̈ z}-X_{t a h}\right| \\
& M S E=\frac{1}{n} \sum_{i=1}^{n}\left[X_{g o ̈ z}-X_{t a h}\right]^{2}
\end{aligned}
$$

eşitliklerde $X_{\text {göz }}$ gözlenen (gerçek) değerleri, $X_{\text {tah }}$ ise çapraz doğrulama sonunda tahmin edilen değerleri göstermektedir.

\subsubsection{Tanımlayıcı istatistikler}

Toprak özelliklerinin ve nem ölçümlerinin ortalama, minimum, maksimum, standart sapma, değişim katsayısı gibi tanımlayıcı istatistikleri belirlenerek dağılımları kontrol edilmiştir. Örneklerin ve nem ölçümlerinin normal dağılıma uygunlukları Kolmogorov-Smirnov testi ile kontrol edilmiştir (SPSS, V21).

\section{Bulgular ve Tartışma}

Toprak özelliklerini belirlemek amacıyla her noktadan horizon derinlikleri dikkate alınarak yapılan örnekleme sonucu Çizelge 1'de verilmiştir. Her iki horizonu da kil bünyeli olan çalışma alanında topoğrafya etkisiyle bazı örnekleme noktalarında toprak özellikleri ayrımlı davranışlar göstermiştir. Engebeli topoğrafya nedeniyle eğimin azaldığ 1 birikme gözlenen bu alanlarda diğer örnekleme noktalarına oranla yaklaşık \%20 daha fazla kil kapsamı belirlenmiştir. Kurak ve yarı kurak iklim şartlarının etkili olduğu araştırma alanında zayıf bitki örtüsü organik madde kapsamının düşük olmasına neden olmuştur. Diğer taraftan topoğrafyaya bağlı olarak birikme alanlarında nem kapsamının yüksek olması bitki gelişimini artırmış, bu noktalardaki kısmen yüksek organik madde değerleri değişim katsayısı değerlerini etkilemiştir. Yüzey horizonunda organik madde değeri \%36 ile en yüksek değişim katsayısı değeri göstermiştir. Her iki horizonda da organik madde kapsamı dışında değişim katsayıları düşük değerler almıştır. Toprak özelliklerinin çarpıklık katsayıları arasında horizonlar için belirgin bir farklılık oluşmamış dağılım benzer bulunmuştur. Her iki horizonda da kil ve organik madde kapsamları negatif, diğer toprak özellikleri pozitif çarpıklık göstermiştir. Yapılan normalite testi sonucunda Bw horizonunda hacim ağırlığı kapsamı dışında tüm toprak özellikleri normal dağılım göstermiştir.

Araştırma alanında Mayıs, Haziran, Eylül ve Ekim aylarında nem ölçümleri yapılmış ve sırası ile profilde toplam $211.93 \mathrm{~mm}, 101.61 \mathrm{~mm}, 121.48 \mathrm{~mm}$ ve 130.49 $\mathrm{mm}$ nem hesaplanmıştır. $\mathrm{Bu}$ dönemde aylık toplam yağışlar Mayıs ayında $61.1 \mathrm{~mm}$, Haziran ayında 12.0 mm, Eylül ayında 16.2 ve Ekim ayında $29.3 \mathrm{~mm}$ olmuştur. Thornthwait $\left(E_{t}\right)$ yöntemi ile hesaplanılan aylık ortalama buharlaşma $18.0 \mathrm{~mm}$ ile en fazla Haziran ayında olmuştur.

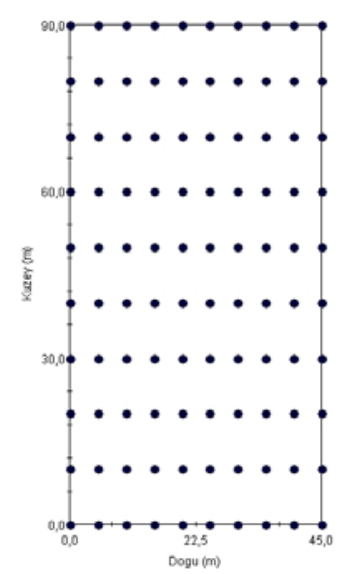

Şekil 1. Toprak nemi örnekleme noktaları Figure 1. Soil moisture sampling points 
Çizelge 1. A $(0-40 \mathrm{~cm})$ ve Bw $(40-85 \mathrm{~cm})$ horizonları toprak tanımlayıcı istatistikleri

Table 1. Descriptive statistics of soil horizons at A $(0-40 \mathrm{~cm})$ and $B w(40-85 \mathrm{~cm})$

\begin{tabular}{|c|c|c|c|c|c|c|c|c|}
\hline Horizon & Özellik & Ortalama & $\begin{array}{c}\text { Std. } \\
\text { sapma }\end{array}$ & Min. & Mak. & Çarpıklık & $\begin{array}{l}\text { Değişim } \\
\text { katsayısı }\end{array}$ & $\begin{array}{l}\text { K-S } \\
\text { test }\end{array}$ \\
\hline $\mathrm{A}$ & Kil, \% & 43 & 5.05 & 31 & 55 & -0.689 & 0.12 & 0.270 \\
\hline \multirow[t]{4}{*}{$0-40 \mathrm{~cm}$} & Silt, \% & 18 & 2.34 & 15 & 25 & 0.399 & 0.13 & 0.154 \\
\hline & Kum, \% & 26 & 4.42 & 18 & 28 & 0.249 & 0.17 & 0.453 \\
\hline & OM, \% & 1.43 & 0.51 & 0.66 & 2.08 & -0.502 & 0.36 & 0.637 \\
\hline & $\mathrm{HA}, \mathrm{g} \mathrm{cm}^{-3}$ & 1.31 & 0.05 & 1.15 & 1.39 & 2.104 & 0.04 & 0.295 \\
\hline Bw & Kil, \% & 44 & 7.83 & 35 & 58 & -0.409 & 0.18 & 0.127 \\
\hline \multirow[t]{4}{*}{$40-85 \mathrm{~cm}$} & Silt, \% & 17 & 2.91 & 13 & 27 & 0.215 & 0.17 & 0.154 \\
\hline & Kum, \% & 21 & 5.03 & 16 & 24 & 0.128 & 0.24 & 0.453 \\
\hline & OM, \% & 0.85 & 0.21 & 0.25 & 1.34 & -0.412 & 0.25 & 0.882 \\
\hline & $\mathrm{HA}, \mathrm{g} \mathrm{cm}^{-3}$ & 1.38 & 0.07 & 1.20 & 1.42 & 2.604 & 0.05 & 0.001 \\
\hline
\end{tabular}

OM: organik madde; HA: kuru hacim ağırlı̆ı; K-S: Kolmogorov-Smirnov normalite testi $(\mathrm{p}<0.05)$

Mayıs ayında ölçülen nem değeri diğer aylarla kıyaslandığında profilde en yüksek ortalama nem değeri belirlenmiştir (Çizelge 2). Seri topraklarının tüm profilde kil kapsamının yüksek olması toprak su hareketini büyük oranda kontrol eden faktör olmuştur. Yağışın yetersiz, buharlaşmanın yüksek olduğu Haziran ve Eylül aylarında profil boyunca çatlaklar oluşmuş, buharlaşma ve bitki su tüketimi nedeniyle nem kapsamı heterojen bir dağılım göstermiş her iki horizonda da yüksek değişim katsayısının oluşmasına neden olmuştur. Hillel (1998) bildirdiği gibi kurak şartlarda toprak bünyesi nedeniyle kararsız nem dağılım şartları oluşmuştur. Bu dönemde A horizonu $\mathrm{Bw}$ horizonuyla karşılaştırıldığında meteorolojik faktörlerden daha çok etkilenmiştir. Ölçüm tarihlerinden önce alınan yağışların etkisi yüksek kil kapsamı nedeniyle profil boyutunda gözlenememiştir. Yüksek kil kapsamı yağışlarla alınan suyun hızla profilde aşağıya ve yukarıya hareketini engellemiş, bu davranış haziran ayında daha belirgin olmuştur. Kurak ve sslak dönemler için profilde belirgin bir çarpıklık eğilimi oluşmamış toprağın nemli olduğu dönemde her iki horizonda da negatif bir çarpıklık oluşurken, kurak dönemlerde pozitif bir eğilim gözlenmiştir.
Benzer bir çalışmada Brocca ve ark. (2007) toprak nem kapsamının sslak şartlarda negatif, kurak şartlarda pozitif dağılım gösterdiğini bildirmiştir. $\mathrm{Bu}$ dönemin başlangıcında topoğrafya nem dağılımını kontrol eden faktör olmuştur. Araştırma alanının kuzeyinde ve batısındaki eğimin azaldığı çukur alanlar nem birikiminin kısmen daha yüksek gözlendiği ve haritalandırıldığı alanlar olmuştur. Kurak dönemde buharlaşma kayıplarının artışıyla birlikte profilde nem dağılımı meteorolojik faktörler tarafından kontrol edilmiştir. Toprak profilinde kurumayla birlikte oluşan çatlaklar, bitki su kullanımı ve kapillar hareket toprak nem dağılımını etkileyerek Bw horizonundan A horizonuna doğru hareketine neden olmuştur. Elde edilen sonuçlar Williams ve ark. (2003), De Lannoy ve ark. (2006) yapmış oldukları çalışmalarla benzer bulunmuştur. Araştırıcılar kuru şartlarda toprak suyunun profil boyunca hareketi ve toprak nem kapsamı dağılımı bitki örtüsü karakteristikleri, toprak özellikleri ve mikrorölyef gibi lokal etmenlerin kontrolüyle son derece heterojen bir yapı oluşturduğunu, ıslak şartlarda ise nem dağılımının daha homojen olduğunu bildirmişlerdir.

Çizelge 2. Acısu serisi horizonları nem değerlerinin tanımlayıcı istatistikleri

Table 2. Descriptive statistics of Aclsu series horizons moisture values

\begin{tabular}{cccccccc}
\hline $\begin{array}{c}\text { Örnekleme } \\
\text { tarihi }\end{array}$ & Ortalama & $\begin{array}{c}\text { Std. } \\
\text { sapma }\end{array}$ & Minimum & Maksimum & Çarpıklık & $\begin{array}{c}\text { Değişim } \\
\text { katsayısı }\end{array}$ & $\begin{array}{c}\text { K-S } \\
\text { test }\end{array}$ \\
\hline A 0-40cm & & & & & & & \\
\hline 02.05 & 19.98 & 3.74 & 12.72 & 27.35 & -0.01 & 0.19 & 0.762 \\
10.06 & 10.17 & 3.35 & 1.72 & 17.50 & -0.22 & 0.33 & 0.956 \\
19.09 & 11.17 & 3.74 & 4.51 & 13.76 & 0.21 & 0.25 & 0.653 \\
27.10 & 12.08 & 1.83 & 8.03 & 16.81 & 0.43 & 0.15 & 0.446 \\
\hline Bw 40-85cm & & & & & & & \\
\hline 02.05 & 18.75 & 3.81 & 10.51 & 26.95 & -0.14 & 0.20 & 0.862 \\
10.06 & 9.13 & 2.96 & 3.78 & 17.67 & 0.76 & 0.32 & 0.288 \\
19.09 & 10.47 & 2.85 & 6.03 & 16.12 & 0.44 & 0.27 & 0.189 \\
27.10 & 12.33 & 2.53 & 6.58 & 17.04 & 0.40 & 0.21 & 0.161 \\
\hline K-S. Kolmogorov Smirnov normalite testi $(\mathrm{p}<0.05)$
\end{tabular}

K-S: Kolmogorov Smirnov normalite testi $(\mathrm{p}<0.05)$ 
Jeoistatistik yöntem kullanılarak her bir örnekleme zamanı için konumsal ve zamansal yapının tanımlanması amaciyla horizon derinliklerinde yarıvariogram modelleri oluşturulmuştur (Şekil 2). Yarıvariogram modellerinin oluşturulmasında yönlere göre olas1 bağımlılık (anizotropi), test edilmiş modeller yönden bağımsız oluşturulmuştur. Ölçüm tarihleri için oluşturulan modellerde konumsal bağımlılık mesafesi kurak dönemle karşılaştırıldığında çok büyük farklılıklar göstermiştir. Dağılımın homojen olduğu sslak dönemde konumsal bağımlılık her iki horizonda da 100 m'nin üzerinde olurken, profilin kuru olduğu haziran ayında konumsal bağımlılık her iki horizonda sirasıyla 8.90 ve $8.34 \mathrm{~m}$ olarak bulunmuştur (Çizelge 3). Islak dönemle karşılaştırıldığında benzer durum Eylül ayı için de gözlenmiştir.
Kurak dönem (Haziran) için geçerli bir model oluşturulmasına rağmen konumsal bağımlılık mesafesinin bu denli kısa olması nem dağılımdaki heterojen yapının bir göstergesidir. Brocca ve ark (2007) yaptıkları çalışmada toprak nem kapsamının konumsal yapısının islak şartlarda daha fazla olduğunu bildirmişlerdir. Küçük havzalarda toprak nem kapsamının konumsal yapısının $20-300 \mathrm{~m}$ arasında değiştiği bildirilmektedir (Mohanty ve ark., 2000). Yarıvariogram modelleri çapraz değerlendirme analizi ile test edilmiş, modeller için oluşturulan ortalama mutlak hata ve hata kareler ortalaması değerleri Çizelge 3 'te verilmiştir. Haziran ayında profilde her iki horizonda diğer ölçüm verilerine oranla yüksek hata değerleri hesaplanmıştır.

Çizelge 3. Acısu serisi horizon nem değerlerinin yarıvariogram modelleri ve çapraz doğrulama analiz sonuçları Table 3. Semivariogram models of Acisu series horizon moisture values and cross validation analysis results

\begin{tabular}{|c|c|c|c|c|c|c|c|}
\hline $\begin{array}{c}\text { Örnekleme } \\
\text { tarihi }\end{array}$ & Model & $\mathrm{C}_{0}$ & $\mathrm{C}_{0}+\mathrm{C}$ & A & $\mathrm{C} / \mathrm{C}_{0}+\mathrm{C}$ & MAE & MSE \\
\hline \multicolumn{8}{|l|}{ A $0-40 \mathrm{~cm}$} \\
\hline 02.05 & Üssel & 5.71 & 22.97 & 178.40 & 0.777 & 2.303 & 7.959 \\
\hline 10.06 & Üssel & 0.01 & 7.16 & 8.90 & 0.957 & 4.011 & 12.067 \\
\hline 19.09 & Üssel & 1.97 & 5.87 & 120.50 & 0.598 & 0.785 & 0.846 \\
\hline 27.10 & Üssel & 1.30 & 5.89 & 137.10 & 0.780 & 1.226 & 2.452 \\
\hline \multicolumn{8}{|l|}{ Bw 40-85cm } \\
\hline 02.05 & Üssel & 9.42 & 19.82 & 165.12 & 0.525 & 1.080 & 1.920 \\
\hline 10.06 & Küresel & 0.01 & 7.96 & 8.34 & 0.787 & 2.131 & 6.618 \\
\hline 19.09 & Üssel & 1.97 & 4.90 & 133.71 & 0.523 & 0.841 & 0.917 \\
\hline 27.10 & Üssel & 3.48 & 12.06 & 221.40 & 0.711 & 1.193 & 2.354 \\
\hline
\end{tabular}

$\mathrm{C}_{0}$ : kontrolsüz etki varyansı; $\mathrm{C}_{0}+\mathrm{C}$ : tepe varyansı; $\mathrm{C} / \mathrm{C}_{0}+\mathrm{C}$ : yapısal varyans oranı; $\mathrm{A}$ : etki aralığı (m); MAE: ortalama mutlak hata; MSE: hata kareler ortalaması

Blok kriging yöntemi ile oluşturulan nem dağılım haritalarında toprak nem değeri her iki horizonda da konumsal ve zamansal olarak değişim göstermiştir (Şekil 3).

Birçok araștırmacının (Williams ve ark., 2003; De Lannoy ve ark., 2006) elde ettiği bulgulara benzer şekilde toprak nem kapsamı bünye, bitki örtüsü, topoğrafya, meteorolojik şartlar gibi birçok faktör tarafindan kontrol edilmektedir.

Toprak yüzey şartlarının atmosfer ile doğrudan ilişkisi nedeniyle A horizonunda toprak nem değerleri düzensiz bir dağ $11 \mathrm{~lm}$ göstermiştir $(0-40 \mathrm{~cm}-\mathrm{b})$. Profildeki yüksek kil kapsamı nem ölçümü yapılan haziran, eylül ve ekim aylarında düşen yağışların (sırasıyla $12 \mathrm{~mm}, 44.1$ $\mathrm{mm}$ ve $28 \mathrm{~mm}$ ) profil boyunca hareketini engellemiş, buharlaşma kayıpları, kapillar hareket Bw horizonunda haziran ve eylül ayları için heterojen bir dağılım oluşmasına neden olmuştur (40-85 $\mathrm{cm} \mathrm{b}$ ve $\mathrm{c}$ ). $\mathrm{Bu}$ dönemde topoğrafya nem dağılımını kontrol eden parametre olurken profilde yeterli nem olduğu durumlarda konumsal yapı daha homojen bir dağılım göstermiş, bu durum dağılım haritalarına da yansımıştır (0-40 cm a, c ve d).

Eğimli topoğrafya üzerinde bulunan araştırma alanında toprak bünyesi bu dönem için nem dağılımını kontrol eden parametre olmuştur.

Haziran ayında kurak dönemle birlikte artan buharlaşma ve profilde gözlenen çatlaklar nem dağılımını heterojen hale getirmiştir (Şekil 3b).

Haziran ayında her iki horizonda diğer aylarla karşılaştırıldığında yüksek MAE ve MSE değerleri göstermiştir. Yüzey horizonu hata değerleri meteorolojik faktörler nedeniyle Bw horizonundan daha yüksek bulunmuştur. Küçük MAE ve MSE değerleri toprak nem değerinin ölçüm tarihleri için doğru tahmin edildiğini göstermektedir. 

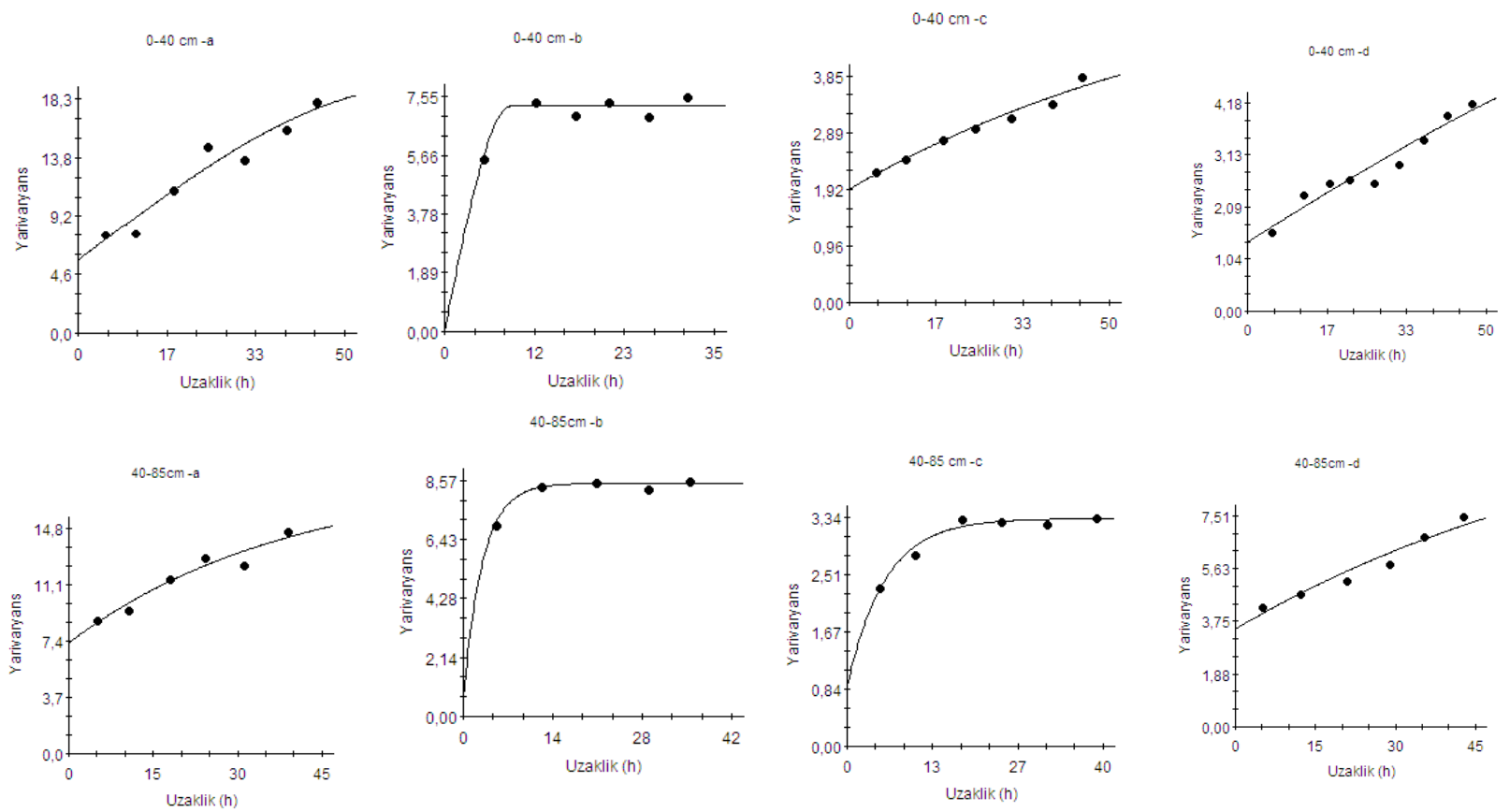

Şekil 2. Acısu serisi horizon nem değerleri için olușturulan yarıvariogram modelleri Figure 2. Soil moisture semivariogram models of Acisu series horizons
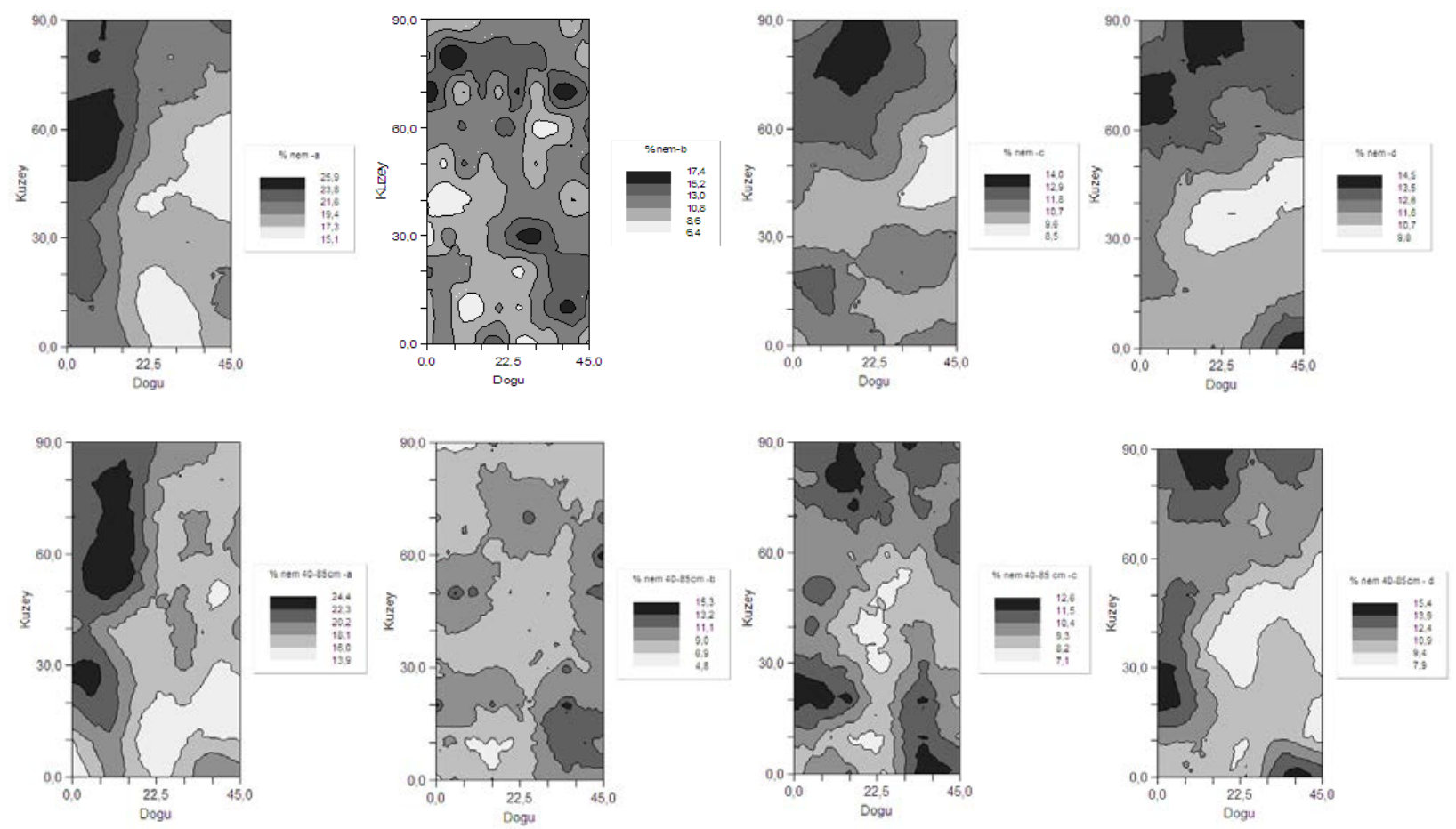

Şekil 3. Acısu serisi horizon nem değerleri için oluşturulan dağılım haritaları Figure 3. Soil moisture distribution maps of Acisu series horizons 
Araştırma süresince yapılan ölçümler toprak nem kapsamının konumsal ve zamansal olarak, toprak bünyesi, bitki örtüsü, meteorolojik şartlar ve topoğrafya gibi birçok faktöre bağlı olarak değiştiğini göstermiştir. Toprak nem dağılımını etkileyen birincil faktör toprak bünyesi olarak belirlenmiştir. Islak dönemlerde toprak nem kapsamı homojen bir dağılım gösterirken, meteorolojik faktörlerin etkisiyle kurak dönemlerde nem dağılımı heterojen olmuştur. Yağışların fazla olduğu dönemlerde eğim boyunca yatay akışın gözlenmesi her iki horizonda da olası gözükmektedir. Kurak şartlara doğru topoğrafyanın etkisi daha belirgin hale gelmektedir. Kurak şartların gözlendiği ve buharlaşmanın yüksek olduğu dönemlerde nem dağılımı topoğrafik ve meteorolojik faktörler tarafindan kontrol edilmiştir. Bu dönemler için oluşturulan yarıvariogram modelleri küçük konumsal bağımlılık mesafeleri göstermişlerdir.

Bu sonuç, hem tarımsal hem de hidrolojik çalışmalar için son derece önemli olan ve birçok parametrenin etkilediği toprak nem kapsamının dinamik davranışı nedeniyle konumsal yapısının tek bir ölçümle açıklanmasının mümkün olmadığını göstermiştir. Söz konusu çalışmalar için altlık oluşturmak, planlama ve uygulama çalışmalarında doğru sonuçları elde edebilmek için kuru ve 1slak toprak şartlarını içine alan ölçümlerin tüm nem çalışmaları için mutlaka yapılması gerekmektedir.

\section{Teşekkür}

Bu proje Tarımsal Araştırmalar ve Politikalar Genel Müdürlüğü (TAGEM) tarafından desteklenmiştir.

\section{Kaynaklar}

Baskan, O., Kosker, Y., Erpul, G., 2013. Spatial and temporal variation of moisture content in the soil profiles of two different agricultural fields of semiarid region. Environmental Monitoring and Assessment. 185(12):10441-10458

Blake, G.R., Hartge, K.H., 1986. Bulk Density and Particle Density. In : Methods of Soil Analysis, Part I, Physical and Mineralogical Methods. Pp: 363-381. ASA and SSSA Agronomy Monograph no 9( $\left.2^{\text {nd }} e d\right)$, Madison.

Bouyoucos, G.J., 1951. A recaliberation of the hydrometer method for making mechanical analysis of soils. Agronomy Journal, 43: 435-438.

Brocca, L., Morbidelli, R., Melone, F., Moramarco, T., 2007. Soil moisture spatial variability in experimental areas of central Italy, J. Hydrol. 333: 356-373.

Cosh, M.H., Jackson, T.J., Starks, P., Heathman, G.C., 2006. Temporal stability of surface soil moisture in the Little Washita River Watershed and its applications in satellite soil moisture product validation. Journal of Hydrology 323: 168-177.
De Troch, F.P., Troch, P.A., Su, Z., Lin, D.S., 1996. Application of remote sensing for hydrological modelling. In: Abbott, M.B., Refsgaard, J.C. (Eds.), Distributed Hydrological Modelling. Kluwer Academic Press, pp. 165-192.

De Lannoy, G.J.M., Verhoest, N.E.C., Houser, P.R., Gish, T.J., Meirvenne, M.V., 2006. Spatial and temporal characteristics of soil moisture in an intensively monitored agricultural field $\left(\mathrm{OPE}^{3}\right)$. J Hydrol. 331: 719-730.

Dengiz, O., Başkan, O. 2005. Ankara Güvenç Havzası Topraklarının Temel Özellikleri ve Sınıflandırılması. Selçuk Üniversitesi Ziraat Fakültesi Dergisi. 19 (37): 27-36.

Endale, D.M., Fisher, D.S., Schomberg, H.H., 2005. Soil water regime in space and time in a small Georgia Piedomont catchment under pasture. SSSAJ. 70: 113.

Famiglietti, J.S., Rudnicki, J.W., Rodell, M., 1998. Variability in surface soil moisture content along a hillslope transect: Rattlesnake Hill, Texas. J Hydrol. 210: 259-281.

Fares, A., Temimi, M., Morgan, K., Kelleners, T.J., 2013. In-situ and remote soil moisture sensing technologies for vadose zone hydrology. Vadose Zone J. 12 (2).

Gamma Design Software., 2014. GS ${ }^{+}$Geostatistics for the Environmental Sciences. Version 9. Plainwell, Michigan. USA.

Gardner, W.H., 1986. Water content. In Klute, A., ed., "Methods of Soil Analysis, Part 1: Physical and Mineralogical Methods”, Monograph No. 9, Am. Soc. Argon. Madison, WI.

Grayson, R.B., Western, A.W., 1998. Towards areal estimation of soil water content from point measurements: time and space stability of mean response. J. Hydrol. 207: 68-82.

Hillel, D., 1998. Environmental soil physics. San Diego, USA: Academic. $765 \mathrm{p}$.

Junior, V.V., Carvalho, M.P., Dafonte, J., Freddi, O.S., Vazques, E.V., Ingaramo, O.E., 2006. Spatial variability of soil water content and mechanical resistance of Brazilian ferralsol. Soil Till. Res., 85: 166-177.

Jackson, M.L., 1958. Soil Chemical Analysis. Prentice Hall Inc., Englewood Cliffs, N.J.

Mohanty, B. P., Skaggs, T. H., Famiglietti, J. S., 2000. Analysis and mapping of field-scale soil moisture variability using high resolution ground based data during the Southern Great Plains 1997 (SGP97) hydrology experiment. Water Resources Research, 36: 1023-1032.

Robinson, D.A. et al., 2008. Advancing process-based watershed hydrological research using near-surface geophysics: a vision for, and review of, electrical and magnetic geophysical methods. Hydrol. Process. 22 (18): 3604-3635.

Soil Survey Staff. 1999. Soil Taxonomy. A Basic of Soil Classification for Making and Interpreting Soil Survey. USDA Handbook No: 436, Washington D.C. 
SPSS. 2012. IBM SPSS Statistics for Windows, Version 21.0. Armonk, NY: IBM Corp.

Tekeli, İ.Y., ve Babayiğit, G., 2004. Ankara Yenimahalle Güvenç Havzası yağış ve akım karakteristikleri. Tarım ve Köyişleri Bakanlığı, TAGEM Ankara Araştırma Enstitüsü yayınları.

Thornthwaite, C.W., 1948. An approach to a rational classification of climate. Geographical Review 38: 55-94.

Wang, J., Fu. Bojie., Qui, Y., Chen, L.., Wang, Z., 2001. Geostatistical analysis of soil moisture variability on Da Nangou catchment of the loess plateau, China. Environmental Geology. 41: 113-120.

Williams, A.G., Ternan, J.L., Fiztzjhon, C., De Alba, S., and Perez-Gonzales, A., 2003. Soil moisture variability and land use in a seasonally arid environment. Hydrological Processes, 17:225-235.

Zhu, Q. et al., 2012. Monitoring and prediction of soil moisture spatial-temporal variations from a hydropedological perspective: a review. Soil Res. 50 (8): 625-637. 